\title{
Announcements
}

\section{MEMBERS OF UNDERREPRESENTED GROUPS: REVIEWERS FOR JOURNAL MANUSCRIPTS WANTED}

If you are interested in reviewing manuscripts for APA journals, the APA Publications and Communications Board would like to invite your participation. Manuscript reviewers are vital to the publication process. As a reviewer, you would gain valuable experience in publishing. The $\mathrm{P} \& \mathrm{C}$ Board is particularly interested in encouraging members of underrepresented groups to participate more in this process.

If you are interested in reviewing manuscripts, please write to Leslie Cameron at the address below. Please note the following important points:

- To be selected as a reviewer, you must have published articles in peerreviewed journals. The experience of publishing provides a reviewer with the basis for preparing a thorough, objective review.

- To select the appropriate reviewers for each manuscript, the editor needs detailed information. Please include with your letter your vita. In your letter, please identify which APA journal you are interested in and describe your area of expertise. Be as specific as possible. For example, "social psychology" is not sufficient-you would need to specify "social cognition" or "attitude change" as well.

- Reviewing a manuscript takes time. If you are selected to review a manuscript, be prepared to invest the necessary time to evaluate the manuscript thoroughly.

Write to Leslie Cameron, Journals Office, American Psychological Association, 750 First Street, NE, Washington, DC 20002-4242.

\section{SPECIAL ISSUE ON RACE, ETHNICITY, AND THE LAW}

The verdicts in the Rodney King police brutality case and their aftermath highlight the problematic nature of the relationship of race, ethnicity, and the law. They also underscore the necessity of continuing scholarly examination of this relationship. To encourage such scholarship, Law and Human Behavior announces a special section/issue on race, ethnicity, and the law. Theoretical and empirical articles on any aspect of race, ethnicity, law, and legal processes are invited. Deadline for completed manuscripts is February 1, 1993. Manuscript style should conform either to the Uniform System of Citation or the Publication Manual of the American Psychological Association. Send four copies (three prepared for anonymous review) to: Valerie Hans and Ramiro Martinez, Special Issue Editors, Criminal Justice Program, Department of Sociology and Criminal Justice, University of Delaware, Newark, Delaware 19716. For more information contact: Professor Hans (302) 831-8231, or Professor Martinez (302) 831-2291. 